\title{
Rádio, populismo e cultura: Brasil e Argentina (1930-1955)
}

Dóris Fagundes Haussen

Professora FAMECOS/ PUCRS eFABICO/ UFRGS. Doutora em Ciências da Comunicação ECA/ USP
O RÁDIO, desde sua consolidação, a partir dos anos 30/40, tem sido utilizado das mais diversas formas, com as mais diferentes finalidades: pelo Estado1; por guerras de independência e resistência; por partidos políticosesindicatos; por movimentossociais, religiosos e ecológicos. Seu papel político é inegável, seja qual for a sua posição. Para que se compreenda o seu real significado, no entanto, é preciso estudar a fundo o contexto em que atua - as condições sócio-políticoeconômico eculturais. N estesentido, no caso específico de Brasil e Argentina, estas são condições prévias para que haja um entendimento do papel político desempenhado pelorádiosobosgovernosde Getúlio Vargas e Juan Perón.

O surgimento da radiodifusão na A mérica Latina, na década de 20 , e a sua consolidaçãoapartir dosanos 30, dá-se quase paralelamente ao início dos movimentos populistas. Estes, por sua vez, no caso de Brasil eA rgentina, devem-se principalmente ao esgotamento do modelo econômico agroexportador eao início do direcionamento para as atividades industriais. Ao mesmo tempo, verifica-se a crise da hegemonia da burguesia oligárquica e do sistema institucional liberal vigente o que dá chance ao surgimento do populismo² como resposta aumvazio no poder correspondenteàquebra dessa hegemonia.

Embora o aparecimento do rádio não tenharelação comostipos degovernoàépoca, mas sim com o avanço das pesquisas tecnológicas que vinham sendo realizadas desde o século anterior, rádio e populismo desenvolvem-sequaseque simultaneamente em ambos os países. É preciso, no entanto, levar em conta que o populismo brasileiro começa a consolidar-se efetivamente, com Getúlio Vargas, a partir do Estado N ovo, em 
1937. JánaA rgentina, o sistemaéimplantado com a eleição de Juan Domingo Perón, em 1946. Para PRADO (1981), esta defasagem de alguns anos entre os populismos brasileiro e argentino deve-se ao fato de que no Brasil a Revolução de 30 corresponde a uma ruptura na hegemonia política da oligarquia cafeeira que deixa um vazio no poder preenchido, então, pelo populismo varguista. $\mathrm{Na}$ A rgentina, um gol pe conservador derruba o presidente Irigoyen e permite às oligarquias exportadoras manterem-se no poder até o gol pe de 1943, que oportuniza a ascensão do populismo peronista em 1946.

Assim, embora o início do sistema populista ${ }^{3}$ nos dois países tenha uma certa diferença de tempo, parte do seu período "áureo" coincide: de1951-55, quando Peróné reeleito na Argentina e Vargas é então el eito pelo voto no Brasil ${ }^{4}$. Ao mesmo tempo, o rádio passa, também, por sua época deglória - 1945/ 1955. Rádio epopulismovivem, desta forma, seus tempos de apogeu e declínio - o rádio, entre outras razões, devido ao surgimento da televisão e, o populismo, às modificações ocorridas nas condições histórico-econômico-sociais dos dois países, o que levaria Vargas ao suicídio em 1954 e Perónàrenúnciaem 1955, o mesmoocorrendo com João Goulart (1961-1964) que ao ser deposto encerra um ciclo populista brasileiro com a chegada dos militares ao poder. No caso argentino, o peronismo mesmo após a queda dePerón em 1955, seu retorno em 1973 ea sua morteem 1974, manteveorganizações fortes, ligadas principal mente aos sindicatos operários.

Quantoàscaracterísticas do populismo, Ianni (1989, p. 105) aponta quesetrata deum movimento de massas, com partido político policlassista, sendo o sindicato tutelado pelo poder público e a liderança carismática, havendo, também, "autilização delinguagem demagógica, nacionalismo econômico, desenvolvimentismo, reformismo, governo populista, democracia populista, ditadura populista e Estado populista".

Numa visão mais abrangente, Laclau (1978, p. 182) considera que o populismo "surge historicamenteligado a uma crise do discurso ideológico dominantequeé, por sua vez, parte de uma crise social mais geral". Para ele, esta crise podeser tanto o resultado deuma cisão no bloco do poder, em queuma classe ou fração de uma classenecessita, para afirmar sua hegemonia, apelar ao povo contra aideol ogiavigenteem seu conjunto, quanto o resultado de uma crise na capacidade do sistema para neutralizar os setores dominados, significando uma crise do transformismo.

Martin-Barbero (1987), por seu turno, consideraser necessário para o entendimento desse sistema, fazer-se uma retrospectiva histórica do processo de modernização dos anos 30-50, sendofundamental acompreensão do surgimento em cena das massas urbanas para o projeto político populista.

Modernização significa, nos anos 30, a adequação das economias dos países latinoamericanos às exigências do mercado mundial oque, por suavez, seproduz entreoutros fatores, mediante a substituição de importações, possível somente com base na organização dos mercados nacionais. N essa unificação do mercado, vão jogar um papel fundamental as tecnologias de comunicação: "a um país o unificam tanto ou mais que as estradas e os trens, o telégrafo, o rádio e o telefone. Pois fazer um país não é só uma questão de economia... é também projeto político e cultural"(ibid, p.183).

$O$ alcancee o sentido dastecnologias de comunicação em relação à cultura, nesse momento, remetem, então, ao movimento social que dá origem ao populismo: o aparecimento das massas urbanas, constituídas em sujeito social justamente a partir da idéia denação. "Elas se reconhecem e são o conteúdo daquele novo sujeito social queéonacional", conformeBarbero. O projeto nacional, por sua vez, somente é possível mediante a comunicação, o encontro entre massas populares e Estado. O populismo desses anos resultou, assim, na organização de poder que deu forma ao compromisso entre as novas massas urbanas e o estado.

A pressão dessas massas pelas suas 
demandas é o que as torna "visíveis": o que era privilégio de uma minoria no campo da habitação ou da saúde, de educação ou da diversão éagora reclamado como um direito das maiorias. E não é possível tornar efetivo estedireitoao trabal ho, àsaúdeou à educação sem massificá-los, isto é, sem dar acesso social às massas. (ibid.p.183)

E é justamente na formulação dessas novas demandas, no seu encontro com o discurso nacional populista, que vão jogar um papel chave as "novas" tecnologias de comunicação desse momento: o rádio, em todos os países, e o cinema em alguns. Elas vão tornar possível, assim, a emergência de uma novalinguagem edeum novo discurso social, o discurso popular-massivo.

O rádio vai ser fundamental para a gestação do sentimento nacional, natradução da idéia de nação em sentimento e cotidianidade. Umsentimento nacional queo rádio dessa época não destrói: o de sentir-se parte de uma região. O nacional foi, nesses anos, uma experiência peculiar: "a de descobrir-sehabitantedeumpaísmaisamplo egrandequesecompartecom outras regiões; foi isso mas, ao mesmo tempo, o início da destruição dessa pluralidade"(I bid, p. 184).

Em síntese, as "novas" tecnologias de comunicação dessa primeira etapa têm sua relação com a cultura mediada pelo projeto estatal de modernização, um projeto eminentementepolíticomastambémcultural: não era possível transformar estes países em nações sem criar neles uma cultura nacional.

\section{Os dois presidentes e as suas táticas}

Getúlio Vargas e Juan Perón nunca se viram pessoalmenteemesmoasuacorrespondência não foi muito freqüente (ao contrário do primeiro governo Vargas, em que ele e o presidenteJ usto além dese corresponderem, visitaram-semutuamente). Noentanto, Perón mantinha admiração por Vargas, até por desenvolver um estilo de governo - embora constitucional mente-semelhanteao primeiro período do presidente brasileiro.
"Nenhum dos dois era devoto dos fastídios da democracia; ambos haviam bebido daságuas do fascismo eintuíam que era nas massas despossuídas onde radicavamseus destinospolíticos. Tanto o brasileiro como o argentino queriam conseguir um desenvolvimento autônomo para seus países ainda que se vissem obrigados a transigir a cada momento. Perón, finalmente, via em Getúlio um animal de sua mesma espécie, dos que serenovavamcom o apoio massivo e clamoroso do povo. Em junho de 1950 o presidente argentino escrevia a Vargas "Eu penso como trabal hista que'ele‘voltará; assim o espero e assim o desejo de todo o coração."(Luna, 1990, p. 23)

Emboranuncasetivessem visto, tinham um excelente intermediário, João Baptista Luzardo, três vezes embaixador do Brasil em Buenos Aires, que mantinha um bom relacionamento com Perón. O queestenão se apercebeu foi que "o Vargas da quarta presidência não era tão forte como antes" (Ibid, p.24). O próprio ministro brasileiro das Relações Exteriores, João N eves da Fontoura, não achava interessante uma aproximação maior do Brasil com a Argentina naquele momento, oquepoderiaser mal interpretado pelos Estados Unidos. O embaixador da A rgentina no Brasil, J. Isaac Cooke, em 1953, alertavaqueembora Vargasfossefavorável à Argentina, já não dispunha da liberdade operacional do período anterior equea força maior estava com o parlamento ea imprensa.

Perón, naquele momento sonhava com uma união aduaneira e econômica com o maior número possível de países latinoamericanos. Para isso, sua máquina de propagandadivulgavanotíciasfavoráveisao seu regime em toda a América Latina, especialmente no Chile e no Brasil, países com os quais esperava contar. Seu intento foi iniciado com o Chile, que o apoiava. Nesse momento, no entanto, devido às relações com os Estados Unidos, a grande imprensa brasileira da época, principalmente 0 Globo, 
O Estado de São Paulo e a Tribuna da Imprensa condenavam a iniciativa. E um possível encontro com Vargas reduziu-se às notícias contráriasquePerón recebeu pelaimprensae a visita do jornalista Geral do Rocha, enviado por Getúlio, informando que a situação no Brasil estava muito difícil e que o pacto era impossível (Ibid, 1990, p. 26). O sonho de integração latino-americana de Perón ficou, então, reduzido a um pacto defronteiras com o Chile.

A admiração de Perón por Vargas é atribuída, assim, em parte à simpatia inicial de ambos - mesmo em períodos diversos pelos regimes autoritários, principalmenteo fascismo. O culto ao líder, recurso bastante explorado por VargasduranteoEstado N ovo, foi utilizado por Perón eEvita, principal mente depois de 1950. A onipresença, através de material de divulgação - pelo rádio, através de fotos, revistas e jornais, e a atribuição de qualidades excepcionais aos chefes também foram muito usadas.

Os dois presidentes lançaram mão de serviços de propaganda - no Brasil o DIP tinha esta função, na A rgentina, a Secretaria del mprensael nformação. N oBrasil, os meios decomunicação continuaramcomseusdonos - mas havia a censura prévia e elementos do DIP para fiscalizar (durante o primeiro período de Vargas, pois durante o segundo, o DIP havia sido dissolvido pela Constituição de 1946). Na Argentina, Perón tomara conta detodos os meios devolvendo após os rádios aos respectivos donos mas com uma censura férrea - ninguém se atrevia a divulgar o que não fosse do interesse do governo, até praticamente o seu final.

Paralelamente, criaram-se novas técnicas eestilos deorganização eliderançaa demagogia e o carisma tornaram-se essenciais para captar as massas assalariadas das cidades. E surgiu, também, o princípio da "paz social", da "harmonia entre as classes sociais", em que o Estado desempenhou um papel fundamental. O nacionalismo popular, por seu lado, foi altamenteestimulado, masa sua utilização nos dois países apresentou diferenças uma vez que as formas de articulação do movimento trabal hista foram diversas:

"Novarguismo, a classe trabalhadora é integrada ao regime diretamente através das organizações estatais; não são os sindicatos senão as Secretarias do Ministério do Trabalho o canal direto para as relações entre trabalhadores e Estado. A sequência que leva os trabalhadores a participar do movimento nacional-popular é intermediada primeiro peloEstadoque, desde o início, controla a mobilização e organiza desde cima os sindicatos, que funcionam como um mero apêndice do poder."(Rodrigues, apud Murmis e Portantiero, 1987) ${ }^{5}$

Por seu turno, no peronismo, aindaque o movimento trabal hista fosse integrado ao Estado e que o poder assumido pelos organismos públicos para a efetivação desse processo fosse decisivo, os sindicatos eram pré-existentes ao governo populista e cumpriam uma função de mediação entre os trabalhadores e o poder político, que era reconhecida. Assim, qualquer análise de um movimento nacional-popular, surgido como proposta política a um processo de rápida industrialização tem que levar sempre em conta o grau de complexidade da estrutura social no momento prévio ao populismo. E um dos indicadores mais significativos para estudar a relação classe trabalhadora e nacionalismo popular é o nível de desenvolvimento da organização sindical.

N ocasoargentino houveumfator muito importante: o êxito em constituir uma linguagempopular-democráticaunificadaem nível nacional pôde ser acessível graças à homogeneidade social, uma exceção dentro da América Latina. E as causas foram "a ausência de campesinato, o predomínio esmagador da população urbana, o amplo desenvolvimento das classes médias e o desenvolvimento do sindicalismo operário em todo o país"(Laclau, 1979, p.196)

NoBrasil, por seulado, Vargasnadécada de 30 teve que manobrar com uma coalizão 
bastante complexa de forças contraditórias e só através do Estado Novo, em 1937, pode estabelecer seu domínio pleno no aspecto político.Mas, mesmo então e durante toda a sua carreira política, não conseguiu tornar-se um líder de um movimento unificado e homogêneo como o de Perón: “será sempre, pelo contrário, um articulador de forças heterogêneas, sobreasquais seestabel eceseu controle político através de um complicado sistema de alianças"(Ibid, p. 138).

Essas alianças necessárias e o peso da classe operária - bem menor do que na Argentina- fizeramcomqueo getulismo não fosse genuinamente "populista", uma vez que nos momentos de estabilidade a linguagem deVargastendiaaser paternalista econservadoraenosmomentos decrise," em que os elementos conservadores da coalizão desertam, lança-se resolutamente na via do populismo - isto é, do desenvolvimento do antagonismo latente nas interpelações democráticas"(Ibid, p. 198)

Na questão econômica, a diferença com a situação argentina está principalmente no fato de que naquele país havia uma sólida camada empresarial agro-importadora hegemônica, indicando na área interna, um setor dinâmico e desenvolvimentista e, por outro lado, uma vinculação externa constituindo-se numa dependência. $O$ peronismo efetivou-se, então, "conciliando os interesses de acumulação do setor economicamentedominantecomosinteresses da 'participação' crescente das massas" (Cardoso e Faletto, 1984, p. 99). E isto foi possível principalmente pela situação favorável que o país vivia após a Segunda GuerraM undial, oquefacilitou aascensão do populismo peronista.

No caso brasileiro, a etapa de expansão paraforanão consolidou umsetor empresarial hegemônico, forte e moderno, que neutralizasse 0 poder dos setores agrotradicionaisemenosaindaqueunificasse os setores populares, rurais e urbanos, como uma massa assalariada. Assim, o "Estado surge como um instrumento não só de regulação do sistema industrial mas também como instrumento direto desua constituição, através da criação de empresas públicas, autárquicas ou para-estatais"(Ibid, p. 103).

O populismo no Brasil apareceu, então, como o elo através do qual as massas emergentes mobilizadas pelaindustrialização vincularam-se ao novo esquema de poder. Posteriormente foi convertido na política de massas que impulsionou a manutenção de um esquema de participação política relativamente limitado e baseado principalmentenumafrágil estruturasindical que não afetou as massas rurais nem o conjunto de setor popular urbano.

A simplificação do conceito de "populismo", noentanto, éprecisoser evitada. Pensar-se apenas na questão econômica ou na política, esquecendo-se da cultural é impossível - principalmente quando se trata da questão dos meios de comunicação. No caso argentino, por exemplo, o peronismo encerrava em si vários conflitos que envolviam a própria questão cultural e buscava congregar as classes trabal hadoras que, por suavez, não eram uniformes. Haviao choque entreosinterioranos atraídos pelas ofertas de emprego e as condições de vida de Buenos Aires, equenão eramaceitos pel os portenhos; estes, por sua vez, tinham seus próprios conflitos internos com os imigrantes, não resolvidos. E esta situação aparecia nas manifestaçõesculturais. Umexemploéasérie radiofônica da época, "Os Pérez Garcia”, que tratavado cotidiano deumatradicional família portenha, em que os "cabecitas negras"- os habitantes morenos do interior argentino não apareciam. Por outro lado, na música e em outros programas, assim como nos bailes, o interiorano sefaziapresente. E o peronismo, através desua política populista buscava esta integração, num sentido homogeneizador e nacionalista, assim como Vargas no Brasil. Para Ford (1991) ${ }^{6}$, o fenômeno na A rgentina configurava um modelo industrial moderno frente a um modelo real mente paternalista e "transladar o conceito do circuito econômico ao cultural é um erro".

Estadistinção entreeconômicoecultural na conceituação de populismo, para Ford é 
fundamental. Em relação ao seu país, sobrea questão econômica, considera que se for levada em consideração a redistribuição de renda, queprivilegiou osocial em detrimento de outro tipo de economia,

“. . . talvez aí, sim se possa falar de populismo. Masépreciso muitocuidado quando se fala do cultural. Trata-se de umaquestão muito complicada, colocar rótulos... o peronismo foi um dos tantos processos de administração que sofreu a Argentina, com seus conflitos, suas características... o populismo,em certa medida,éapresençado Estado emnível político eeconômico. Em nível cultural significou o ingresso de toda uma área que estava a descoberto na Argentina."(Idem)

No caso brasileiro, o projeto cultural do governo, de cunho nacionalista, fazia parte da orientação de resguardar os valores nacionais, incentivando principalmente a abordagem de temas e problemas especificamente brasileiros. Villa-Lobos encarregou-se deorganizar as apresentações musicais nas grandes comemorações cívicas. Também foi o intermediário entre os artistas populares e o governo, convidando-os a participar das realizações do regime. Estes, por sua vez, já tinham, em geral, um bom relacionamento com o governo de Vargas, quefora o autor da Lei dos DireitosA utorais, em 1928, ainda quando deputado pelo Rio Grande do Sul, e que os beneficiava.

Por outro lado, Canclini (1987, p. 37) considera que o peronismo atenuou as desigual dades ao facilitar ao povo o acesso à educação média esuperior, bem como a todo tipo de espetáculos e produtos culturais e de massa. "Mas essa expansão quantitativa, o mesmo que o distribucionismo econômico, não modificou as causas estruturais da desigual dade, nemfoi acompanhadapor uma reelaboração crítica do hábitos culturais do povo". Para o autor, em vários movimentos populistas latino-americanos, a política cultural reproduziu as estruturasideológicas e as relações sociais legitimadoras da identidade entre Estado e Nação?.

Deste modo, no caso específico da utilização do rádio num esquema político populista, o veículo aparece como um instrumento para a divulgação e mediação dessesistema. Instrumento estequeéutilizado deformas diferentes- etambémsemel hantes em alguns pontos - pelos dois governantes populistas, de acordo com o momento (no caso brasileiro, nos dois períodos deVargasa utilização foi diversa) e com a possibilidade do sistema - mas com um objetivo idêntico.

O quelevaaumareflexão sobreo depoimento do radialista argentino Antônio Carrizzo: “NaArgentina, Perónfoi oprimeiro quesedeu contadaimportânciadautilização do rádio. Mas quem está livre de culpa que atire a primeira pedra. Porque todos os governos que vieram depois, à sua maneira, também utilizaram o rádio politicamente" (Carrizzo, 1991) .

\section{Notas}

1 Orádiofoi criadoeusadoporMussolini, naltália(Mussolini, jornalista, foi redator-chefedo A vanti, jornal socialista deMilão, em 1912, antes de se tornar ditador em 1925; criou também a Cincittá); porFranklin D. Roosevelt, em 1933, emsuas" Conversas ao pédo fogo", nos Estados Unidos; e por Hitler, naAlemanha. Em 1933, quando Hitler foi designado Chanceler, os nazistas utilizaram o rádio para propaganda eantes, em 1931, tentaram influenciar na nomeação dos diretores das emissoras.

2 Há muitas discussões sobre o conceito de populismo. No presente trabalho leva-se em consideração, principalmente, as definiçōes de de Weffort (1980), Laclau (1978), lanni (1989) e Martin-Barbero (1987).

3 Quando há referência a "sistema populista", a definição é retirada de Weffort que o define como "estrutura institucional do tipo autoritário e semicorporativa, orientação política de tendêncianacionalista, antiliberal eanti-oligárquica; orientação econômicadetendêncianacionalistaeindustrialista; composição social policlassista mas com apoio majoritário das classes populares" $(1980$, p. 85). 
4 Para Ianni (1989), podese falar em Estado populista na A rgentina com Perón (1946-1955) eno Brasil com Vargas (19371945 e 1951-1954) e com João Goulart (1961-1964).

5 RODRIGUES, Leôncio Martins. 'Sindicalismo y desarollo

en Brasil'. Revista Latinoamericana de Sociologia (66, 1; 27-42)

6 FORD, Anibal. Depoimento à autora, Buenos Aires, 1991.

7 Canclini (1987) considera que para a política cultural de "estatismo populista"o nacional reside no Estado e não no povo.

8 CARRIZZO, Antônio. Depoimento à autora,Buenos Aires, 1991.

\section{Bibliografia}

CANCLINI, Néstor (org.). Politicas culturales en America Latina. Mexico, Grijalbo, 1987.

CARDOSO, Fernando Henrique e FALETTO, Enzo. Dependência e desenvolvimento na América Latina. Rio de Janeiro, Zahar, 1973, Za. ed.

HAUSSEN, DorisFagundes. 'Rádio ePolítica: temposdeVargas e Perón. São Paulo', tese de Doutorado, ECA/ USP, 1993.

IANNI, Octávio. A formação do estado populista na A mérica Latina. Rio de Janeiro, Civilização Brasileira, 1989, 2a. ed.

LACLAU, Ernest. Política e Ideologia na Teoria M arxista. Rio de Janeiro, Paz e Terra, 1978.

LUNA, Felix. Perón y su tiempo. III. El régimen exhausto. 19531955. Buenos Aires, Ed. Sudamericana, 1990, 4a. ed.

MARTÍN-BARBERO, Jesus. Procesos de comunicación y matrices para salir de la razón dualista. Mexico, FELAFACS, 1987.

MURMIS, Miguel e PORTANTIERO, Juan Carlos. Estudios sobre los orígenes del Peronismo. Buenos Aires, Siglo XXI Ed., 1987, 5a. ed.

PRADO, Maria Ligia. 0 populismo na América Latina. São Paulo, Brasiliense, Tudo éH História, 1981.
WEFFORT, Francisco. 0 populismo na política brasileira. Rio de Janeiro, Paz e Terra, 1980, 2a. ed.

\section{Entrevistas}

CARRIZZO, Antônio. Radialista, iniciou as suas atividades em 1948, na Radio El Mundo, deBuenos Aires. Entrevista realizada em Buenos Aires, setembro de 1991

FORD, Anibal. Escritor, professor da Universidade de Buenos Aires, jornalista (foi editor da Revista Crísis, com Eduardo Galeano). Entrevista realizada em Buenos Aires, setembro de 1991. 